\title{
Androgen deprivation therapy for prostate cancer: indications, contraindications and possible consequences
}

\author{
Alexander Karl* and Badrinath Konety
}

Address: Department of Urology, School of Medicine, University of California-San Francisco, 1600 Divisadero Street, San Francisco, CA 94143, USA

*Corresponding author: Alexander Karl (karla@urology.ucsf.edu).

FI000 Medicine Reports 2009, I:2 (doi: 10.34I0/MI-2)

The electronic version of this article is the complete one and can be found at: http://FI000.com/Reports/Medicine/content/I/2

\begin{abstract}
Androgen deprivation therapy (ADT) has been the mainstay of palliative treatment in advanced and metastatic prostate cancer for many years. It is also increasingly being used in patients with localized disease. Here we review some recent trials that are providing information on its benefits and disadvantages in different circumstances.
\end{abstract}

\section{Introduction and context}

In 2008, prostate cancer will be diagnosed in an estimated 186,320 men in the United States and approximately 28,660 men will die of the disease, according to the US National Cancer Institute [1]. Androgen deprivation therapy (ADT) has historically been the mainstay of treatment in advanced and metastatic disease. Today ADT is also utilized in patients with local disease and especially those with high-risk features undergoing radiation therapy.

Information from the CaPSURE database shows that the use of primary hormonal therapy for men with localized prostate cancer has increased significantly among men with low- and intermediate-risk disease since the 1995 American Urological Association (AUA) guidelines were published [2]. These data were confirmed by a report derived from the Surveillance, Epidemiology, and End Results (SEER)-Medicare database [3].

In general, primary ADT is employed with the goal of providing symptomatic control of prostate cancer for patients in whom definitive treatment with surgery or radiation is not possible or acceptable. The concept of ADT should be distinguished from the use of neoadjuvant hormonal therapy (before radical prostatectomy or radiation therapy) or adjuvant (after radical prostatectomy or radiation therapy) hormonal therapy. The use of luteinizing hormone-releasing hormone (LHRH) agonists, which downregulate LHRH receptors by interfering with the hypothalamic-pituitary-gonadal axis, is now standard in long-term hormonal therapy $[4,5]$. Antiandrogens, in contrast, compete with circulating androgens for binding receptors. Antiandrogens can be used on their own (monotherapy), or in combination with LHRH agonists for combined androgen blockade, or are used to reduce the risk of a testosterone 'flare' that often accompanies the initiation of LHRH.

\section{Different modes of androgen deprivation}

Bilateral orchiectomy (castration) or subcutaneous application of LHRH agonists are the predominant forms of ADT. Goserelin is the most widely studied LHRH agonist. In patients with locally advanced disease, goserelin has been shown to significantly improve overall survival when given as an adjuvant to radiotherapy [6].

\section{Antiandrogen monotherapy}

Non-steroidal antiandrogens are known to affect only the androgen receptor without presenting direct gonadotropic effects. This is part of the explanation of the maintenance of potency in $70-80 \%$ in patients who receive non-steroidal ADT monotherapy. 
A 2000 study pooling two open-label, multicentre studies of identical design has evaluated whether monotherapy with the non-steroidal antiandrogen bicalutamide might be an alternative to medical or surgical castration in patients with locally advanced prostate cancer [7]. In this study, a total of 480 patients with T3-4, Mo disease were randomized to receive either bicalutamide $(150 \mathrm{mg})$ or castration. After a median follow-up time of 6.3 years, mortality was $56 \%$, with no significant difference between bicalutamide and castration in terms of overall survival (HR 1.05; $P=0.70$ ) or time to progression (HR 1.20, $P=0.11$ ). Compared with castration, bicalutamide was better for maintaining physical activity and libido during the entire treatment period and afterwards. The data suggest that bicalutamide $150 \mathrm{mg}$ provides a survival outcome similar to that observed with castration in patients with locally advanced disease.

The 2008 European Association of Urology (EAU) guidelines [8] (Table 1) point out that antiandrogen monotherapy with bicalutamide is comparable to that with LHRH agonists in men with minimal tumour burden. However, the guidelines also state that survival rates are lower in patients with extensive metastatic disease, in whom medical or surgical castration should be favoured.

\section{Complete androgen blockade}

On the basis of data from the most recent systematic reviews and meta-analyses, complete ADT results in a small median survival benefit $(<5 \%)$ compared with monotherapy with LHRH agonists [3, 9]. However, adverse effects leading to withdrawal of patients from therapy also occur more often with combined androgen

\begin{tabular}{|c|c|}
\hline TIa & Not an option (grade $A$ recommendation) \\
\hline TIb-T2b & $\begin{array}{l}\text { Symptomatic patients who need palliation of } \\
\text { symptoms and who are unfit for curative treatment } \\
\text { (grade } \mathrm{C} \text { recommendation) }\end{array}$ \\
\hline T3-T4 & $\begin{array}{l}\text { Symptomatic patients, extensive T3-T4, high PSA } \\
\text { level (>25 ng/ml), unfit patients. Better than watchful } \\
\text { waiting (grade A recommendation) }\end{array}$ \\
\hline $\mathrm{N}+, \mathrm{MO}$ & Standard therapy (grade A recommendation) \\
\hline M+ & $\begin{array}{l}\text { Standard therapy. Symptomatic patients should not } \\
\text { be denied treatment (grade A recommendation) }\end{array}$ \\
\hline \multicolumn{2}{|l|}{ Antiandrogens } \\
\hline $\begin{array}{l}\text { Short-term } \\
\text { administration }\end{array}$ & $\begin{array}{l}\text { To reduce the risk of the flare-up phenomenon in } \\
\text { patients with advanced metastatic disease who are to } \\
\text { receive an luteinising hormone-releasing hormone } \\
\text { agonist (level of evidence: } \mathrm{Ib} \text { ) }\end{array}$ \\
\hline $\begin{array}{l}\text { Nonsteroidal } \\
\text { antiandrogens }\end{array}$ & $\begin{array}{l}\text { Primary monotherapy as an alternative to castration } \\
\text { in patients with locally advanced PCa (level of } \\
\text { evidence: Ib) }\end{array}$ \\
\hline
\end{tabular}

blockade. Therefore, complete ADT is not recommended for routine clinical use as a standard therapy [8].

\section{Intermittent androgen blockade}

The reasoning behind intermittent androgen blockade is to reduce treatment-associated side effects, to influence sensitivity to hormonal treatment and, furthermore, to lower healthcare costs without compromising therapeutic efficacy. Several phase II trials have demonstrated the feasibility of intermittent androgen blockade in metastatic or biochemically recurrent disease, with prostatespecific antigen (PSA) response rates and symptom improvement similar to those of complete androgen blockade.

According to the 2008 EAU Guidelines [8] (Table 1) it is possible to offer intermittent androgen blockade to selected patients, but results from randomized trials are still lacking. A minimum induction period of 7 months with continuous hormonal therapy and a PSA response of $<4 \mathrm{ng} / \mathrm{ml}$ seems to be required for a successful intermittent regimen.

\section{Recent advances}

There are different approaches and aims in using androgen deprivation. One is the palliation of symptoms in metastatic cancer and the reduction of risk for potentially severe sequelae of advanced disease (spinal cord compression, pathological fractures, ureteral obstruction and extraskeletal metastasis) [10, 11]. Asymptomatic patients with metastatic disease can also benefit from immediate androgen deprivation as it could defer progression to a symptomatic stage and prevent serious complications related to disease progression [9].

In lymph-node-positive patients, immediate institution of androgen deprivation has demonstrated prolongation of progression-free survival. Messing et al. [12] analyzed the appropriate timing and impact of ADT on survival in men with node-positive prostate cancer who have undergone radical prostatectomy and pelvic lymphadenectomy compared with those who received ADT at disease progression. At median follow-up of 11.9 years, those patients who received immediate ADT had a significant improvement in overall survival (HR 1.84, $P=0.04$ ), prostate-cancer-specific survival (HR 4.09, $P=0.0004$ ), and progression-free survival (HR 3.42, $P<0.0001)$.

This study demonstrated that early ADT benefits patients with nodal metastases who have undergone prostatectomy and lymphadenectomy, compared with those who receive deferred treatment. In his evaluation [13] of this study, Faculty of 1000 member Adam Kibel poses the 
question of whether the initiation of androgen ablation at the time of prostate-specific antigen (PSA) elevation would provide the same survival benefit as immediate androgen deprivation. To our knowledge there is no study published so far that could give a definite answer to this question. Further prognostic studies are needed to evaluate the optimum timing for ADT in detail to reduce side effects of hormonal therapy as best possible.

The study of Messing et al. [12] is also cited in the 2008 EAU Guidelines on prostate cancer [8]. It is stated that although the results showed a significant survival advantage for immediate ADT in lymph-node-positive patients, it must be acknowledged that most patients had gross nodal disease and that $70 \%$ also had positive margins and/or seminal vesicle invasion. It is unclear whether adjuvant androgen deprivation in patients with minimal nodal involvement would result in the same positive results.

A recently published Cochrane Database analysis evaluated ADT in regard to different primary therapy approaches [14]. Four studies were included in this analysis that evaluated adjuvant hormonal therapy following radiotherapy. There was reported a significant improvement in overall survival at 5 and 10 years. Also disease-specific survival and disease-free survival were statistically improved in favour of adjuvant hormones at 5 years.

According to three evaluated studies, adjuvant hormonal therapy did not show a statistically significant advantage in overall survival in patients who underwent primary radical prostatectomy. However the study of Messing et al. [12] showed a statistically significant improvement in disease specific survival at 5 years and 10 years.

Recently, Conti et al. [15] presented a Cochrane database analysis comparing intermittent ADT and continuous ADT in prostate cancer patients. Five randomized studies were included involving a total of 1382 patients. All patients included were diagnosed with advanced prostate cancer (T3 or T4). A subgroup analysis showed no significant differences in biochemical progression in a comparison of intermittent and continuous ADT for patients with Gleason scores 4-6, 7, and 8-10.

No differences between intermittent and continuous ADT were found in regard to adverse effects - gastrointestinal disturbances, gynecomastia (abnormal breast enlargement) and asthenia. ADT did show a significant benefit $(P=0.008)$ in reducing impotence. In their conclusions the authors state that there are only limited data on side effects and insufficient data regarding overall survival, disease-specific survival, or disease progression in the current literature [10].

\section{Implications for clinical practice Complications and contraindications}

A chosen treatment for prostate cancer can yield benefits, but it can also harm. As stated above, ADT has shown to be beneficial and is indicated in different stages of this disease. On the other hand, ADT can result in a multitude of endocrine and general complications [16]. Some may affect patients' quality of life, and others contribute to increased risks for serious health concerns.

Sexual side effects (erectile dysfunction and loss of libido) are the well recognized adverse effects of ADT. Eligible patients (see above) could benefit in terms of erectile dysfunction from non-steroidal antiandrogen therapy. In an Italian study comparing bicalutamide 150 mg monotherapy with combined androgen blockade, significantly fewer patients in the monotherapy group reported erectile dysfunction (69.2 vs $93.3 \%$, respectively, $P=0.0002$ ) or loss of libido (59.6 vs $85.5 \%$, respectively, $P \leq 0.01$ ) compared with combined androgen blockade [16]. There is also evidence that bicalutamide $150 \mathrm{mg}$ can preserve physical capacity in comparison with castration $[7,16]$.

One adverse event that is commonly observed (around $80 \%$ ) is the incidence of hot flashes, which may not abate over the course of ADT. Drugs such as estrogens, progestin megestrol acetate, and venlafaxine have been shown to decrease hot flashes and associated symptoms [17].

Loss of bone mineral density associated with castration can be reduced with biphosphonates, as reported by Aus et al. [17]. Also, bicalutamide has shown to maintain bone mineral density [18].

Complications also include recognized physiologic effects, including gynecomastia and breast pain. Gynecomastia and breast pain are the most common adverse effects associated with treatment of non-steroidal antiandrogens. In randomized studies, treatment with tamoxifen has been shown to significantly reduce the incidence of breast pain and gynecomastia [17]. Therapeutic radiotherapy showed to improve symptoms, but more effectively for breast pain than for gynecomastia.

Recently, insulin resistance, hyperglycemia, and metabolic syndrome have emerged as metabolic complications of castration and may be responsible for increased cardiovascular mortality in this population [18]. Cardiovascular disease and diabetes are known to be the 
leading causes of non-cancer-related death in patients who survive cancer. It is known that men with prostate cancer have higher rates of non-cancer mortality than the general population [19].

A study published by Keating et al. [20] in 2006 analyzed whether the use of ADT with a LHRH agonist is associated with an increased incidence of diabetes and cardiovascular disease. This study observed a cohort of 73,196 patients from the linked database of SEERMedicare who were diagnosed with local or locoregional prostate cancer in the period 1992-1999. Cox proportional hazards models were used to assess whether treatment with LHRH agonists or orchiectomy was associated with diabetes, coronary heart disease, myocardial infarction and sudden cardiac death. The authors report that $36.3 \%$ of men received a LHRH agonist and $6.9 \%$ underwent bilateral orchiectomy in this cohort. After prostate cancer diagnosis, 3,917 men (5.4\%) were diagnosed with myocardial infarction and 3,301 (4.5\%) experienced sudden cardiac death. Among 64,721 patients without prevalent diabetes, $10.9 \%$ developed diabetes and among 59,748 without prevalent coronary heart disease, $25.3 \%$ developed coronary heart disease. LHRH agonist use was associated with increased risk of incident diabetes (adjusted HR 1.42, $P<0.001$ ), coronary heart disease (adjusted HR 1.16, $P<0.001$ ), myocardial infarction (adjusted HR 1.11, $P=0.03$ ), and sudden cardiac death (adjusted HR 1.34, $P=0.004)$. In contrast, men who underwent orchiectomy for ADT were diagnosed more often with diabetes (HR 1.34, $P<0.001$ ), whereas no significant risk was detected for coronary heart disease, myocardial infarction or sudden cardiac death (all $P>0.20$ ).

The authors concluded that LHRH agonist treatment for men with loco-regional prostate cancer might be associated with an increased risk of incident diabetes and cardiovascular disease. Therefore the benefits of LHRH agonist treatment should be weighed against these potential risks.

In an evaluation [21] of this paper, Faculty of 1000 member Robert Dreicer states that this important study of patients with loco-regional prostate cancer treated with either gonadotropin-releasing hormone (GnRH) agonists or orchiectomy demonstrated a significant association of GnRH therapy with diabetes, heart disease and sudden cardiac death and an association of orchiectomy with diabetes.

Similar results were presented by Tsai et al. [22], who analyzed 1,015 patients who received ADT. In their study, patients older than 65 years who were treated with
ADT in addition to radical prostatectomy had a 5-year cumulative incidence of cardiovascular death of 5.5\% and those treated with radical prostatectomy alone had a $2.0 \%$ incidence of cardiovascular death. Also, younger patients who were treated with radical prostatectomy and received ADT were reported with a 5-year cumulative incidence of cardiovascular death of $3.6 \%$ compared with $1.2 \%$ without ADT.

It is therefore important for clinicians to anticipate these complications and to initiate measures to prevent or minimize them [22]. Patients who are considered for ADT should undergo careful cardiovascular evaluation and receive regular internal check-ups. The risk of ADT has to be balanced for every patient individually.

Generally, physicians should be aware of the far-reaching consequences of ADT and should incorporate strategies for preventing and managing its undesirable side effects into routine practice. The indications for ADT need to be assessed more accurately and recommendations for this therapy restricted more strictly to those categories of patients that have clearly been shown to benefit from it in prospective randomized studies.

\section{Abbreviations}

ADT, androgen deprivation therapy; EAU, European Association of Urology; GnRH, gonadotropin-releasing hormone; HR, hazard ratio; LHRH, luteinizing hormonereleasing hormone; PSA, prostate-specific antigen.

\section{Competing interests}

The authors declare that they have no competing interests.

\section{References}

I. Prostate Cancer: National Cancer Institute, 2008 http://www. cancer.gov/cancertopics/types/prostate

2. Meng MV, Grossfeld GD, Sadetsky N, Mehta SS, Lubeck DP, Carroll PR: Contemporary patterns of androgen deprivation therapy use for newly diagnosed prostate cancer. Urology 2002, 60(Suppl I): 7-II.

3. Cancer Survivorship: Resilience Across the Lifespan. Proceedings of the National Cancer Institute's and American Cancer Society's 2002 Cancer Survivorship Conference. June 2-4, 2002. Washington, DC, USA. Cancer 2005, I 04(Suppl): 2543-645.

4. Seidenfeld J, Samson DJ, Hasselblad V, Aronson N, Albertsen PC, Bennett CL, Wilt TJ: Single-therapy androgen suppression in men with advanced prostate cancer: a systematic review and meta-analysis. Ann Intern Med 2000, 132:566-77. [Erratum: Ann Intern Med 2005, | 43:764-65.]

5. Samson DJ, Seidenfeld J, Schmitt B, Hasselblad V, Albertsen PC, Bennett CL, Wilt TJ, Aronson N: Systematic review and metaanalysis of monotherapy compared with combined androgen blockade for patients with advanced prostate carcinoma. Cancer 2002, 95:361-76.

6. Bolla M, Collette L, Blank L, Warde P, Dubois JB, Mirimanoff RO, Storme G, Bernier J, Kuten A, Sternberg C, Mattelaer J, Lopez Torecilla J, Pfeffer JR, Lino Cutajar C, Zurlo A, Pierart M: Long-term 
results with immediate androgen suppression and external irradiation in patients with locally advanced prostate cancer (an EORTC study): a phase III randomised trial. Lancet 2002, 360:103-6.

7. Iversen P, Tyrrell CJ, Kaisary AV, Anderson JB, Van Poppel H, Tammela TL, Chamberlain M, Carroll K, Melezinek I: Bicalutamide monotherapy compared with castration in patients with nonmetastatic locally advanced prostate cancer: 6.3 years of followup. J Urol 2000, 164:1579-82.

8. Heidenreich A, Aus G, Bolla M, Joniau S, Matveev VB, Schmid HP, Zattoni F; European Association of Urology: EAU guidelines on prostate cancer. Eur Urol 2008, 53:68-80.

9. Loblaw DA, Virgo KS, Nam R, Somerfield MR, Ben-Josef E, Mendelson DS, Middleton R, Sharp SA, Smith TJ, Talcott J, Taplin M, Vogelzang NJ, Wade JL3rd, Bennett CL, Scher HI; American Society of Clinical Oncology: Initial hormonal management of androgen-sensitive metastatic, recurrent, or progressive prostate cancer: 2006 update of an American Society of Clinical Oncology practice guideline. J Clin Oncol 2007, 25: 1596-605.

10. Ross RW, Xie W, Regan MM, Pomerantz M, Nakabayashi M, Daskivich TJ, Sartor O, Taplin ME, Kantoff PW, Oh WK: Efficacy of androgen deprivation therapy (ADT) in patients with advanced prostate cancer: association between Gleason score, prostate-specific antigen level, and prior ADT exposure with duration of ADT effect. Cancer 2008, I I 2:1247-53.

II. Janoff DM, Peterson C, Mongoue-Tchokote S, Peters L, Beer TM, Wersinger EM, Mori M, Garzotto M: Clinical outcomes of androgen deprivation as the sole therapy for localized and locally advanced prostate cancer. BJU Int 2005, 96:503-7.

12. Messing EM, Manola J, Yao J, Kiernan M, Crawford D, Wilding G, di'SantAgnese PA, Trump D; Eastern Cooperative Oncology Group study EST 3886: Immediate versus deferred androgen deprivation treatment in patients with node-positive prostate cancer after radical prostatectomy and pelvic lymphadenectomy. Lancet Oncol 2006, 7:472-9.

FI000 Factor 6.0 Must Read Evaluated by Adam Kibel 27 Nov 2006
13. Adam Kibel: Faculty of 1000 Medicine, 27 Nov 2006 http://www. fl000medicine.com/article/id/I047/97/evaluation.

14. Kumar S, Shelley M, Harrison C, Coles B, Wilt TJ, Mason MD: Neoadjuvant and adjuvant hormone therapy for localised and locally advanced prostate cancer. Cochrane Database Syst Rev 2006, Oct 18: CD006019.

15. Conti PD, Atallah AN, Arruda H, Soares BG, El Dib RP, Wilt T): Intermittent versus continuous androgen suppression for prostatic cancer. Cochrane Database Syst Rev 2007, Oct 17: CD005009.

16. Boccardo F, Rubagotti A, Barichello M, Battaglia M, Carmignani G, Comeri G, Conti G, Cruciani G, Dammino S, Delliponti U, Ditonno P, Ferraris V, Lilliu S, Montefiore F, Portoghese F, Spano G: Bicalutamide monotherapy versus flutamide plus goserelin in prostate cancer patients: results of an Italian Prostate Cancer Project study. J Clin Oncol 1999, 17:2027-38.

17. Aus G, Abbou CC, Bolla M, Heidenreich A, Schmid HP, van Poppel H, Wolff J, Zattoni F; European Association of Urology: EAU guidelines on prostate cancer. Eur Urol 2005, 48:546-5I.

18. Sieber PR, Keiller DL, Kahnoski RJ, Gallo J, McFadden S: Bicalutamide $150 \mathrm{mg}$ maintains bone mineral density during monotherapy for localized or locally advanced prostate cancer. J Urol 2004, I7I:2272-76.

19. Brown BW, Brauner C, Minnotte MC: Noncancer deaths in white adult cancer patients. J Natl Cancer Inst 1993, 85:979-87.

20. Keating NL, O'Malley AJ, Smith MR: Diabetes and cardiovascular disease during androgen deprivation therapy for prostate cancer. J Clin Oncol 2006, 24:4448-56.

21. Dreicer R: Faculty of $\mathbf{1 0 0 0}$ Medicine, II Oct 2006 http://www. fl000medicine.com/article/id//046/75/evaluation.

22. Tsai HK, D'Amico AV, Sadetsky N, Chen MH, Carroll PR: Androgen deprivation therapy for localized prostate cancer and the risk of cardiovascular mortality. J Natl Cancer Inst 2007, 99:1516-24.

FI000 Factor 3.0 Recommended

Evaluated by Olof Akre 22 Nov 2007 